\title{
BREVE ANTOLOGÍA PERSONAL DE FREDY GAMBETTA
}

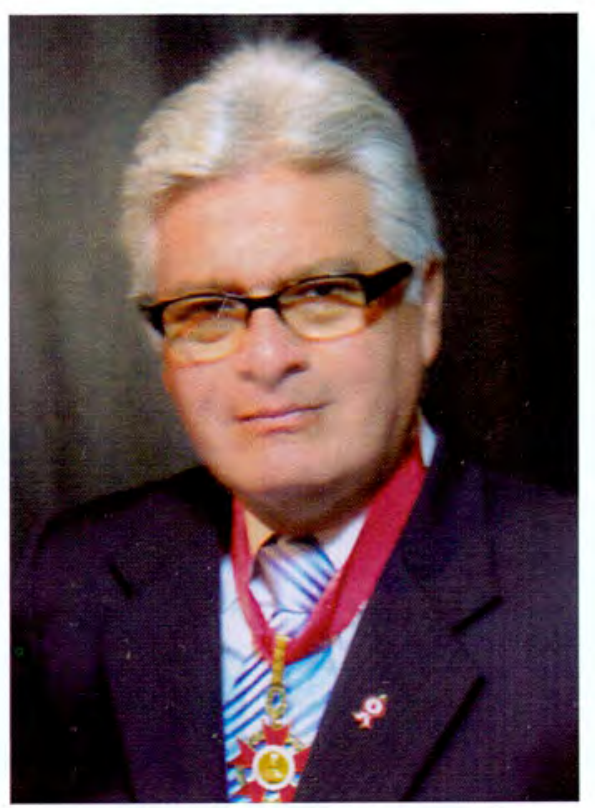

Fui un niño solitario entre personas mayores. No me criaron mis padres. Leí desde la primera infancia y escribí poesía. Mi primer poema reconocido fue el elogio lírico a la reina de mi colegio (1964). Gané un concurso de cuentos, en mis años de estudiante universitario (1967).

Publiqué catorce poemarios con el título Sobre todo el Amor (1997). Son poemas dedicados a mi ciudad natal; al amor; a mártires como Victor Jara; a personajes biblicos; a animales; a mí gato Nabucodonosor; a varias ciudades, al frenesi de la vida.

He escrito cuentos, un ensayo biográfico, investigado épocas de la historia de

Tacna y ensayado escribir obras de teatro. Y crónicas, cientos de crónicas.

Sigo escribiendo poesía.

Pertenezco a la que se puede llamar "generación de los 70" En esta breve antología recojo poemas éditos. Desde 1997 otros versos esperan que les "devuelva la mirada" para ver la luz. 
Fredy Gambetta es un poeta, periodista cultural, investigador de la historia tacneña, conocido como el Cronista de Tacna. Se inició escribiendo columnas culturales en el diario La Voz de Tacna, en 1967. Ganador de los Juegos Florales en Cuento, en la Universidad Nacional San Agustín. Escribe, desde 1973, la columna dominical Rumor del Caplina, en el diario Correo. Consultor de Imagen Corporativa en Electrosur S.A., Egesur, Mineroperu S.A., Universidad Privada de Tacna, Zofratacna y Southern Perú.

Fue Asesor del Despacho Ministerial y Director General de Comunicaciones del Ministerio de Educación. Director del Archivo Regional de Tacna; Jefe del Proyecto Cultural del Gobierno Regional de Tacna, Director de la Casa Basadre y Sub Gerente de Educación y Cultura de la Municipalidad Provincial de Tacna.

La República de Bolivia le impuso la Orden del Libertador Simón Bolivar, en el Grado de Comendador y la Asociación de Clubes Departamentales del Perú lo distinguió con la Palma de Oro al Ciudadano Ilustre (2013).

Ha recibido distinciones de los gobiernos municipales de Arequipa, Moquegua y Puno. Ostenta la Medalla de la Cultura, de la Filial Tacna del INC; la Medalla de la Cultura "Francisco de Paula Gonzales Vigil"; el Premio Fomento a la Cultura, de la Municipalidad Provincial de Tacna; la Medalla de Honor al Mérito de la Universidad Privada de Tacna; es Socio Honorario del Club Unión de Tacna y de la Filial de la Asociación Nacional Pro Marina.

Ha dictado conferencias en universidades de Perú, Bolivia, Cuba y Chile. Sus poemas se han publicado en revistas de España, Estados Unidos, Puerto Rico, Colombia, Ecuador, Venezuela, Argentina, Bolivia, Brasil. Es corresponsal del periódico que la comunidad Ligure edita en Genova, Italia. Varios de sus poemas y crónicas han sido traducidos al italiano, inglés, portugués y japonés.

Ha publicado 19 libros. (Poesía, crónicas, una novela histórica, dos ensayos biográficos y otro de episodios de la Guerra con Chile). Es destacado promotor cultural y escritor de documentales. 


\title{
LO QUE TU ERES
}

Amada, tu recuerdo viene unido al olor de los huertos de Tacna.

Tus pequeñas manos

que bordan la alegría de mis días

se hicieron de humedecidos pétalos.

Tú voz es un largo concierto de gorriones

y tú eres un sueño, una paloma,

la brisa que se enreda

jugueteando entre las flores.

("NUEVO AMOR, NUEVOS POEMAS" - 1975)

III

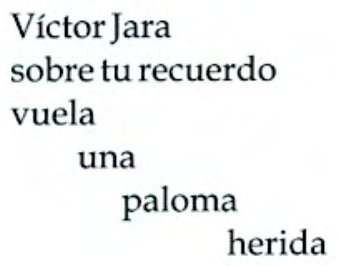

("TE RECUERDO, VÍCTOR" - A la memoria del compositor y cantante Victor Jara, asesinado en el Estadio Chile el 12 de setiembre de 1973 - 1977)

\section{EL GRAN MAESTRE ESPERABA LA LLUVIA}

El Gran Maestre esperaba la lluvia sentado sobre mil volúmenes de antiguo cuero

y hojas de apolillada piel de serpientes tropicales.

\section{EPIGRAMA II}

\author{
A la oveja \\ que escapó del rebaño, \\ primero le enviaron un memorándum, \\ después una notificación \\ $\mathrm{y}$, por último, \\ la muerte en un sobre con cintas rosadas.
}




\title{
CANTO CUARTO
}

\author{
Felino \\ ojos de cielo, \\ libre correteas \\ por los sentimientos \\ más puros \\ de los que habitamos \\ tu casa.
}

(“OCHO CANTOS PARA NABUCODONOSOR" - Para mamá María que velaba los sueños de Nabucodonosor, mi gato - 1974)

\section{VUELO DE GAVIOTA}

\section{A Livio Gómez}

Remonta en alto vuelo una gaviota sola.

Sobre el infinito

universo de una ola.

No hay soledad más alta que la de una gaviota sola.

\section{EL ORIGEN}

Mucho antes que el sol de los Inkas en las entrañas del Arunta naciera;

mucho antes de que el Chupiquiña y el Takora dieran los primeros alaridos; una lluvia de estrellas de lo alto del cielo descolgóse y entre un bosque de vírgenes vilcas bordó en lo profundo un nombre: TACNA i

("RUMOR DEL CAPLINA" - Al doctor Jorge Basadre - 1977)

\section{JEREMIAS}

Como dice la letra del valse:

"llora, llora corazón, llora si tienes porqué" 


\section{EL DIOS DE LA MUERTE}

Acurrucado en las esquinas vomita sangre.

Aguarda la salida de los niños en las escuelas.

Impaciente se retuerce a los pies de los enfermos. No cree en las estaciones. Ignora la luna, el sol y las estrellas. Escapa de las probetas y tiene la desvergüenza de vivir cómodamente en los medicamentos.

\section{CASA DERRUÍDA}

Honda soledad de la casa

derruida

Pisadas que no cesan

de trizar el silencio

Voces que anidan en el aire.

Pensamiento fijo en ángulos inesperados

Casa derruida: Cuerpo desollado y abandonado al olvido.

\section{LOS ORÁCULOS NO ANUNCIARON}

Los oráculos no anunciaron ésta orgía de sangre.

No esperaba el calendario un día de mañanas abaleadas.

Mi pueblo tenía su vestido de batalla que estrenó en una hora inesperada. 


\section{NADA INVENTAMOS}

Nada inventamos en el mundo hoy día.

Todo no es más que luz repetida.

No se inventa más tristeza ni alegría.

No se abre dos veces la misma herida.

Necios aquellos que afirman orgullosos descubrir nuevas canciones, nuevos modos.

Vulgares, tristes, pobres alabanciosos que viven entre palmas y acomodos.

El cuento es el mismo, claro, repetido.

La voz, el tono dicho de otro modo, para cualquier hombre cuerdo es advertido.

Lo obvio como la luz brilla sobre todo.

A qué entonces poses y falsa elegancia.

A qué buscar con afán lo singular

si la vulgar y ufana arrogancia

vale menos que aguja en el pajar.

("EN EL VIEJO TONO" - Al doctor César Angeles Caballero - 1980)

\section{UN BURRO FUNCIONARIO}

\section{Ayer encontré un burro en cómodo escritorio.}

No miraba más allá de sus narices.

Decía que con coces se arreglaría el mundo.

Había registrado su nombre en las carpetas personales,

En las tarjetas de entrada y de salida, en la puerta de su casa, sobre el escritorio, en las corbatas de seda, en los calcetines de lana, en los anchos calzoncillos en el libro de visitantes ilustres.

A pesar de todo, se ponía furioso cuando lo llamaban por su nombre. 


\section{HE SIDO FELIZ}

Alguna vez fui feliz bajo la lluvia a mis pies la tierra húmeda.

Fui feliz oyendo el ladrido lejano de los perros con la luna arriba como una ilusión redonda.

Alguna vez fui feliz al mediodía cercano al lomo de los cerros detrás de árboles violetas.

Fui feliz oliendo el pan viendo luces confundidas de bares al amanecer celeste.

Alguna vez fui feliz mascando chicle y fresca lavanda para llegar al encuentro con la luz de esos ojos que alumbran a pesar del tiempo perdido.

Fui feliz descubriendo calles en remotas ciudades adivinando la oscuridad de las chozas sonámbulas perdidas en la alta noche.

He sido feliz en varios instantes de mi variada vida.

En medio de perdidas voces, humo de cigarrillos compañeros, amarillo vaho de la cerveza.

No me quejo. He sido feliz, de una manera propia. 